\title{
Abuso policial, discrecionalidad y tecnologías de vigilancia en América Latina
}

\author{
Police abuse, discretionality and surveillance \\ technologies in Latin America \\ Lucía Carmina Jasso López* \\ Instituto de Investigaciones Sociales-unam, Ciudad de México, México \\ ORCID: http://orcid.org/00o0-0002-8036-II26 \\ Carolina Jasso González ** \\ El Colegio de México, Ciudad de México, México \\ ORCID: https://orcid.org/o0oo-000I-7764-4072
}

Resumen

El abuso policial constituye una problemática de interés sociológico y un objeto de preocupación social derivado de la "nueva visibilidad" que adquieren las interacciones de violencia entre la policía y la población, como resultado de los diferentes usos de las tecnologías de vigilancia, particularmente de formas como la vigilancia desde abajo o sousveillance. A partir de la sistematización y el análisis de datos cualitativos, se discute el impacto de las tecnologías de vigilancia en 129 casos de abuso policial registrados en video en América Latina. Los resultados indican que la videovigilancia se ha convertido en un mecanismo relevante para documentar y determinar en qué casos se cometieron violaciones graves a derechos humanos; sin embargo, la discrecionalidad institucional, las fallas en los registros y la facultad de los agentes estatales para decidir cuándo registrar o no una práctica arbitraria imposibilita que se conviertan en mecanismos de control efectivos para sancionar y evitar las prácticas de arbitrariedad.

Palabras claveः videovigilancia, nueva visibilidad, violencia, letalidad policial, sousveillance.

\footnotetext{
Abstract

Police abuse constitutes a problem of sociological interest and an object of social concern derived from the "new visibility" acquired by violent interactions between the police and the population, as a result of the different uses of surveillance technologies, particularly of forms such as surveillance from below or sousveillance. Based on the systematization and analysis of qualitative data, we discussed the impact of surveillance technologies in 129 cases of police abuse recorded on video in Latin America. The results indicate that video surveillance has become a relevant mechanism to document and determine in which cases serious human rights violations were committed; however, institutional discretion, deficiencies in registries, and the power of state agents to decide when or not register an arbitrary practice, make it impossible to become effective control mechanisms to sanction and avoid arbitrary practices.
}

Keywords: Surveillance, police lethality, violence, new visibility, sousveillance.
ISSN-OI85-4259; e- ISSN: 2007-9I76

2I/atc3/jassolopezl/jassogonzalezc 


\section{Introducción}

125 de mayo de 2020 la policía de Minneapolis utilizó la fuerza letal durante
el arresto de George Floyd. Los hechos se convirtieron en noticia interna-
cional y de inmediato la opinión pública se volcó hacia la discriminación racial, la arbitrariedad y la violencia que prevalece en las instituciones policiales, con efectos sociales inimaginables.

Varías cámaras de vigilancia captaron sus últimos minutos de vida y los hechos fueron registrados desde diferentes ángulos; ${ }^{1}$ aun así, no se tiene claridad sobre todo lo que ocurrió. ${ }^{2}$ No obstante, las imágenes difundidas muestran que se cometió abuso policial y que el uso excesivo de la fuerza provocó su muerte, lo que en consecuencia desató importantes movilizaciones en Estados Unidos y en otros países.

Dos días después, en Tijuana -ciudad fronteriza de México- un policía municipal de forma similar al caso de George Floyd sometió y asfixió a Yair López. Los hechos, también quedaron registrados en video y la evidencia permite observar la forma en que el policía coloca su pie sobre la víctima cuando se encontraba esposado y sin mostrar resistencia. Así sucesivamente, decenas de abusos policiales han sido registrados en video en América Latina sin tener el mismo eco que el caso estadounidense, pero evidenciando la necesidad de supervisión y control policial para evitar este tipo de hechos.

En este artículo se plantean dos objetivos principales. Por una parte, se busca sistematizar $\mathrm{y}$ analizar distintos casos de abuso y letalidad policial registrados por cámaras de videovigilancia que tuvieron lugar en América Latina en la última década.

1 Particularmente el video captado por un "espectador" es el que ha sido más difundido y se considera que "probablemente jugó un papel importante en las protestas en Minneapolis y el país" (McLaughlin, 2020).

2 En uno de los videos el propio vehículo de Floyd bloquea parte de la vista de la cámara, así como un vehículo de la policía no permite ver la escena en su totalidad (McLaughlin, 2020). 
Por otra parte, se problematiza respecto a los efectos de las tecnologías de vigilancia sobre el abuso policial (pública-privada y fija-móvil) y se discute acerca de las narrativas sociales e institucionales que se construyeron en torno a estas imágenes y los efectos sociales generados. Entre otras preguntas, las interrogantes que guían esta investigación son: ¿cuál ha sido el efecto social de los videos que registran abuso policial en América Latina?; ¿qué características tienen este tipo de videos?; ¿han contribuido a disminuir la discrecionalidad policial?

Como hipótesis se plantea que la visibilidad del abuso policial a través de los videos impacta en la percepción de la sociedad sobre este problema público e incrementa la demanda de mayor control y rendición de cuentas en las policías; sin embargo, en el caso de América Latina no ha logrado reducir en su totalidad la discrecionalidad profundamente arraigada y aceptada en las instituciones policiales de la región.

Para contextualizar la investigación, en el primer apartado se discute sobre el abuso y la violencia policial en América Latina. Posteriormente se hace una revisión de la literatura especializada y de la evidencia empírica sobre la relación entre las tecnologías de vigilancia y el trabajo policial. Al respecto, cabe precisar que la mayor parte de los textos son anglosajones, debido a que en estos países se ha difundido más ampliamente el uso de las tecnologías de vigilancia en las funciones policiales; no obstante, los hallazgos reportados son relevantes para mostrar las posibilidades, limitaciones y realidades del uso de estas tecnologías en la región.

La investigación se apoya de la documentación, sistematización y análisis de casos de abusos policiales $-y$ algunos militares- que comparten una característica común: los hechos se registraron en videos que fueron difundidos a través de los medios de comunicación u otras plataformas. La principal fuente de información para acceder a estos casos son los reportes y notas de prensa que documentaron y difundieron los videos, así como reportes de queja y recomendaciones emitidas por organismos públicos de derechos humanos (OPDH). La búsqueda y sistematización de la información permitió construir una base de datos compuesta por 129 casos: 92 compilados en la prensa que tuvieron lugar en Argentina, Bolivia, Brasil, Chile, Colombia, Costa Rica, Ecuador, El Salvador, Guatemala, Honduras, México, Nicaragua, Panamá, Paraguay y Perú durante la última década y 37 registrados por los OPDH en México. ${ }^{3}$

3 Tres de los casos registrados por los OPDH en México también fueron ampliamente difundidos en medios de comunicación y por lo tanto forman parte de la base de datos de América Latina documentada a partir del análisis hemerográfico. 


\section{Abuso y violencia policial en América Latina}

La violencia policial en América Latina constituye una problemática continua y de larga data. No obstante, en las últimas décadas el abuso y la letalidad de las instituciones policiales se ha convertido en un fenómeno, no solo de interés sociológico, sino de preocupación social de particular relevancia en la región. Factores como el incremento del delito y el surgimiento de nuevas formas y dinámicas delictivas, el aumento en la percepción de inseguridad y el enfoque punitivo que ha acompañado a las estrategias y políticas públicas implementadas en varios países latinoamericanos para la contención de la criminalidad (Sozzo, 2017) han contribuido de forma significativa a agravar el problema.

En la literatura con frecuencia se reconoce que las policías conciben la violencia como un recurso legítimo y ordinario en el cumplimiento de sus funciones, en sus encuentros cotidianos con la población y, por lo tanto, las prácticas violentas y la victimización no son reconocidas como comportamientos que quebranten la ley, sino como "externalidades del trabajo policial" (Cano y Fragoso, 2000; Stinson, 2020; Fassin, 2016; Jobard, 20II). Asimismo, en el estudio de las políticas públicas hay un cuerpo importante de literatura que refiere a las policías como "burocracias a nivel de calle" (Dussauge, Cejudo y Pardo, 2018) con inevitables márgenes de discrecionalidad en su operación en el día a día, que incluso tienen posibilidades de incidir en el rumbo de las políticas.

En síntesis, se argumenta que la violencia se presenta como una consecuencia de la experiencia ocupacional y es vista como un recurso profundamente arraigado $y$ aceptado en términos de los fines definidos al interior de las instituciones policiales (Westley, 1953). Sin embargo, aun cuando la violencia se presenta como un recurso compartido y definitorio del trabajo policial, no se puede asumir que se ejerza de igual forma ni obviar sus particularidades y los incentivos sociales e institucionales que intervienen en el ejercicio de la fuerza y la violencia.

En este sentido, a diferencia de otros contextos en los que el abuso o las interacciones entre la policía y la población mediadas por la violencia presentan una baja proporción (Smith, Kaminski, Rojek, Alpert y Mathis, 2007), América Latina se ha caracterizado en los últimos años por registrar una alta incidencia en la muerte de civiles por agentes estatales.

Investigaciones recientes (Pérez, Silva y Cano, 2019: 29; UNODC, 2019) han destacado la especificidad que adquiere el fenómeno de la letalidad policial en países de la región como El Salvador y Venezuela, en donde la tasa de civiles muertos a consecuencia de intervenciones policiales es superior o cercana a la tasa mundial de 
homicidios (6.I homicidios por cada I00,000 habitantes). Por otra parte, los datos disponibles sobre muertes intencionales por agentes de policía en comparación con los homicidios intencionales de policías presentan proporciones de 6.6 en el caso de El Salvador y de I9.9 para Brasil; es decir, por cada homicidio intencional de un agente de policía en El Salvador, se presentan 6.6 homicidios intencionales de civiles por parte de la policía; mientras que en Brasil, por cada homicidio intencional de un agente estatal, se registran 19.9 homicidios de civiles por elementos de la policía (UNODC, 2019: 74).

Cano y Fragoso (2000), en su análisis sobre el caso de Brasil, observan la ocurrencia de intervenciones policiales con altos niveles de victimización y letalidad, así como patrones que privilegian interacciones y encuentros mediados por el uso excesivo de la fuerza, en lugar de la inmovilización o el arresto y registros que sugieren la ocurrencia de ejecuciones arbitrarias, al igual que en Colombia (Bolaños y Benavides, 2017), México y otros países de América Latina. La evidencia actual sobre el caso de Brasil indica un incremento en el número de víctimas de letalidad durante intervenciones policiales en las que las policías militares son la principal autoridad responsable (Pérez, Silva y Cano, 2019: 29).

El abuso policial en la región, sin embargo, no se limita a la letalidad, sino que supone un continuo entre el empleo de modos de coerción no físicos como las amenazas, la extorsión y el uso de la fuerza física como la tortura, la desaparición forzada o la privación arbitraria de la vida. La violencia que ejerce la policía se presenta también, como surgiere Pita (2019: 88), en forma de un "hostigamiento" cotidiano que admite prácticas ampliamente aceptadas y remite a distintos niveles y grados de violencia y discrecionalidad que anteceden a formas más extremas incluidas en "repertorios de violencia policial", que se han favorecido por la conjunción de factores regionales como la impunidad, el giro punitivo, el liderazgo militar en tareas de seguridad interna y la ausencia de mecanismos de control robustos sobre las instituciones policiales.

\section{La discrecionalidad del trabajo policial}

Las instituciones policiales son organizaciones sumamente problemáticas en términos de los efectos sociales vinculados con su facultad para el ejercicio de la fuerza $y$ la violencia. De acuerdo con Monjardet, la tarea fundamental de la policía es aplicar los recursos de la fuerza con el propósito de asegurarle al poder su dominio en las relaciones sociales internas (2010:27). 
$\mathrm{Al}$ ser la institución depositaria del monopolio legítimo de la violencia física, la policía se vuelve un "mecanismo para la distribución no negociable de la fuerza coercitiva” (Bittner, 1970: 42), justificada a partir de las exigencias de una situación específica. En otras palabras, la fuerza y la violencia pueden ser utilizadas siempre que se juzgue necesario y es la policía la que decide a quién castigar y cómo hacerlo, cuándo ejercer la fuerza o la violencia y en qué grado, incluso decidir en qué momento ejercer la fuerza letal. En gran medida, la discrecionalidad es inherente a la función policial (Dussauge, Cejudo y Pardo, 2018).

En el trabajo policial, como señala Goldstein (1960: 543), las decisiones suelen acompañarse por una "baja visibilidad" o discrecionalidad; la policía no siempre “invoca al proceso penal”, es decir, a la evaluación respecto a si un acto infringe o no la ley. Esta valoración puede responder a normas formales o a códigos informales de lo que significa el mantenimiento del orden y el trabajo policial, lo que supone, como argumenta Monjardet (2010: 30) que, aun bajo la existencia de un arsenal jurídico robusto, pueden hacerse "presentes las peores infamias policiales", incluso tratarse de prácticas totalmente legítimas bajo los códigos informales al interior de la institución.

En los últimos años, frente al abuso y la violencia de las instituciones de seguridad en distintos contextos, la demanda social de supervisar el comportamiento de la policía ha conducido a implementar reformas tendientes a develar su "baja visibilidad". La exigencia social de contar con un registro del trabajo policial, como sugieren Sandhu y Haggerty (2015:2) cuestiona el axioma de la discrecionalidad ampliamente aceptado en la sociología de la policía para dar paso a nuevas dinámicas de visibilidad resultado del uso de las tecnologías de vigilancia; no obstante, el argumento de Sandhu y Haggerty requiere ser evaluado a la luz de la renuencia de las instituciones policiales a ser vigiladas y a las particularidades de otros contextos como el latinoamericano.

En los estudios sobre la videovigilancia con frecuencia el uso de cámaras y sistemas de video son considerados como mecanismos a través de los cuales es posible observar y, en algunos casos, mediar la interacción de la policía con la ciudadanía. Constituyen dispositivos de saber-poder (Foucault, 2000) que en condiciones específicas permitirían vigilar y frenar los abusos policiales y otras formas de violencia ejercidas por agentes estatales, conductas sumamente difíciles de someter a supervisión y control (Alvarado y Silva, 20II: 446).

Bajo esta línea argumentativa, Mann, Nolan y Wellman (2003) han destacado la necesidad de problematizar y restituir la vigilancia y la videovigilancia como tecnologías para observar a quienes poseen autoridad. Así, las tecnologías de vigilancia, 
más allá de ser dispositivos de seguridad, logran efectos en distintos ámbitos de la vida social (Arteaga, 2016: 196). En este contexto, la sousveillance o la vigilancia desde abajo es relevante porque supone el uso de las tecnologías de vigilancia para hacer frente a las organizaciones burocráticas, mejorando no solo la capacidad de los sujetos de acceder y recopilar datos sobre la vigilancia que se ejerce sobre ellos, sino para "vigilar al vigilante" (Mann, Nolan y Wellman, 2003ः 333).

Respecto a las formas de vigilar a quienes poseen autoridad y los medios a través de los cuales se puede ejercer una vigilancia desde abajo es preciso referir que existen al menos dos tipos y dos modalidades de vigilancia en video. Por una parte existe la videovigilancia pública, financiada y gestionada por instituciones de carácter público y la videovigilancia privada, financiada con recursos propios de hogares, comercios, empresas y se caracteriza por estar gestionada por quienes las pagan. Por otra parte se presenta la videovigilancia fija, colocada en un sitio específico con un ángulo de vigilancia permanente -como las cámaras que se colocan en postes en la trama urbana - y la móvil, que está en constante movimiento, como los drones que se desplazan de un lado a otro de acuerdo con las necesidades del operador, o las cámaras que forman parte de los millones de teléfonos celulares que circulan en las ciudades.

A su vez, existen otras especificidades de la videovigilancia como mediadoras de las interacciones entre la policía y la ciudadanía, que particularmente han sido útiles para su supervisión y control. Por ejemplo, las cámaras corporales (bodycams) que se instalan en los uniformes de los policías. Distintas investigaciones, como se refirió anteriormente, argumentan que estos dispositivos aumentarían la transparencia y la responsabilidad al recopilar imágenes directamente en el lugar de los hechos; se trata en gran medida de hacer públicas "las interacciones ocultas" (Joh, 20I8) entre la policía y los civiles, "eliminando la necesidad de una casualidad fortuita al grabar de forma continua el campo de visión de los policías en el terreno y en el día a día de sus actividades cotidianas" (Mateescu, Rosenblat y Boyd, 2016: 122).

Asimismo, se considera que el uso de las cámaras corporales no solo contribuye a generar nuevas dinámicas de visibilidad sino, como observa Brown (2016: 296), puede producir efectos importantes en el comportamiento policial respecto al uso de la fuerza. En primera instancia, mediante una "influencia disciplinadora", así como a través de un peso sobre la decisión de cuándo y cómo utilizar la fuerza como resultado de un proceso de internalización de tipo disuasorio.

En este mismo tenor, la presencia de estas cámaras se asocia con la resolución más rápida de los casos, la reducción de papeleo y la mejora en la sensación de seguridad 
de la sociedad (Duffy, Mattias, Rahma y Timalsina, 2020; Botta, 20I4). ${ }^{4}$ Incluso en el discurso público, el uso de estos dispositivos se ha posicionado como ejemplo de "buena práctica", como lo constata la recomendación que la Relatora Especial de la ONU dirige a un gobierno de América Latina respecto a la necesidad de equipar a las patrullas, las unidades y a los efectivos de seguridad con dispositivos GPS, cámaras portátiles y de videograbación, particularmente a aquellas policías que registren altos índices de uso letal de la fuerza (ONU, 20I8: 20I).

Esta recomendación ha sido adoptada de forma gradual por los gobiernos nacionales y locales en la región. ${ }^{5}$ En México, esta medida se precisa en el artículo i7 del Manual del uso de la fuerza de aplicación común a las tres fuerzas federales (2014), en el que se hace referencia al uso intensivo de cámaras de videograbación y audio para documentar las interacciones e incidentes con la población y fungir como evidencia de que la actuación de la policía y las fuerzas armadas no haya transgredido los derechos humanos. ${ }^{6}$ Se trata en gran medida de un esfuerzo público por hacer de la policía un "trabajador transparente" (Lyon, 1995); sin embargo, en los apartados siguientes se discute acerca de los límites y obstáculos que se presentan frente a esta medida.

En Europa, la policía inglesa "es puntera y pionera" en el uso de estas tecnologías (Fernández, 2019), mientras que Estados Unidos ha sido uno de los países en el que más ha proliferado el uso de cámaras en el ámbito policial. De acuerdo con Joh (2018), esta demanda creció en 2015 después de los incidentes de violencia policial contra civiles en protestas públicas y la muerte del joven Michael Brown. En el caso de la brutalidad policial cometida contra Rodney King en i99i por la policía de los Ángeles, el video registrado por un testigo contribuyó para que los oficiales de policía implicados fueran sometidos a un proceso penal y, como destacan Mann,

4 En una encuesta realizada en Buenos Aires, "unos cuantos manifestaron sentir un cierto placer al mirar las imágenes de las cámaras de VGEP reproducidas en los medios de comunicación, ya que, o bien cumplen una función educativa -enseña lo que hay, los peligros de la calle, para estar prevenidos-, o bien una función tranquilizadora -por lo menos lo agarraron, las cámaras sirven para algo, se hacen cosas-" (Botta, 20I4ः II8).

5 En México el gobierno federal considera como parte de los productos a adquirir con recursos públicos de los fondos y subsidios del Sistema Nacional de Seguridad Pública los "sistemas de grabación portátil en patrulla" y las "cámaras de solapa" para portar en los uniformes de los policías. Se sugiere consultar: http://www.secretariadoejecutivo.gob. $\mathrm{mx} /$ fondos-subsidios/Concertaciones-20I8/Presentaciones_FASP_FORTASEG_20I8.pdf

6 Arteaga (2016:202) refiere que desde 2015 la Secretaría de Seguridad Pública de Tijuana destinó "cámaras personales por cada policía". 
Nolan y Wellman (2003), a un importante debate sobre la necesidad de implementar estrategias para la reducción de la violencia policial.

Sin embargo, un hecho ineludible es que la adquisición de las cámaras por parte de los gobiernos y su uso en las corporaciones policiales no garantiza el control, la rendición de cuentas y la responsabilidad policial. Por una parte, existe la posibilidad de que se incrementen los arrestos de bajo nivel porque los oficiales están presionados a seguir el procedimiento mientras se graba su trabajo (Mateescu, Rosenblat y Boyd, 2016). A lo anterior se suma que como cualquier otro tipo de cámara, están a merced de quien las opere, y si se decide que lo hagan los mismos policías o sus superiores, existe la posibilidad de que las enciendan o apaguen a discreción (Joh, 20I8), e incluso que lleguen a elucubrar formas para evadir o distraer la vigilancia y evitar acusaciones sobre "mala" conducta policial.

En este sentido, también es necesario precisar que es una realidad que "pocos departamentos de policía tienen la capacidad de almacenar de forma segura los datos generados por la vigilancia de sus oficiales" (Joh, 2018: 4). Este es uno de los principales retos de la videovigilancia en el mundo, debido a que no se tiene capacidad de almacenamiento permanente de todas las imágenes captadas (Jasso, 2020), por lo que eventualmente tienen que ser desechadas periódicamente y en algunos casos se borran hechos relevantes.

Aunado a lo anterior, hay que agregar que generalmente los videos permanecen en un sitio custodiado por la misma policía y en parte es la institución la que toma la decisión de qué registrar y presentar como evidencia (Mateescu, Rosenblat y Boyd, 2016; Duffy, Rahma, y Timalsina, 2020); al mismo tiempo, para que las imágenes captadas por las cámaras públicas sean entregadas a los civiles interesados se tiene que solicitar a las autoridades. Así se incrementa el poder de quienes gestionan las tecnologías de vigilancia.

Sin embargo, la evidencia indica que sí se presentan cambios en el comportamiento policial en presencia de las cámaras de vigilancia; prueba de ello son las resistencias que eventualmente surgen para su uso, sobre todo si las reglas no son claras (Joh, 2018). Como argumentan Alvarado y Silva (2011: 465), "las dificultades para la supervisión y el control del trabajo policial son reconocidas en todas partes del mundo" y con gran probabilidad se acrecientan en los países de América Latina donde la corrupción e impunidad permea el quehacer policial.

En este contexto, es relevante destacar la vigilancia que se realiza desde las cámaras de los teléfonos celulares de los civiles. Esta vigilancia se basa en la presencia de un espectador dispuesto a captar la escena de un incidente (Mateescu, Rosenblat y Boyd, 2016: 122) y es capaz de producir mecanismos de solidaridad y cohesión 
(Arteaga, 20r8) en relación con los abusos policiales; en otras palabras, de ejercer una vigilancia desde abajo que obliga a la autoridad a asumir su responsabilidad. De esta forma, periodistas o transeúntes que son testigos de los hechos, graban y comparten las imágenes como una forma de testimonio y protesta y difunden el enojo y hartazgo social ante miles de personas. Este fenómeno también ha sido denominado "contravigilancia" (Lyon, 1995) y se le considera capaz de generar procesos de cuidado y protección, así como formas de participación y reivindicación social.

\section{Discusiones empíricas en torno a las tecnologías de vigilancia y el trabajo policial}

La mayor parte de la literatura sobre tecnologías de vigilancia y la policía se centra en el estudio de las instituciones de seguridad como gestores y operadores para la generación de inteligencia, monitoreo de movimientos sociales, etc. En menor medida se registran trabajos sobre estas tecnologías orientadas a la observación de la policía. Una proporción significativa de la literatura producida es anglosajona.

Elizabeth Joh (2018) reseña la historia de las cámaras corporales en la policía en Estados Unidos. En particular, se enfoca en la oferta y demanda de esta tecnología por parte de las corporaciones policiales, la capacidad de gestión de los datos generados y desde luego las tensiones y resistencias por parte de los policías. En este mismo tenor Duffy, Rahma y Timalsina (2020) analizan la industria encargada de producir estas tecnologías, los costos y características, así como los grupos de interés que convergen en los datos, y proponen un sistema más transparente en el que se pueda mantener la evidencia (Duffy, Rahma y Timalsina, 2020).

También en Estados Unidos, Mateescu, Rosenblat y Boyd (2016) estudian cómo la demanda de una mayor rendición de cuentas fue la motivación más importante para la introducción de estas tecnologías; sin embargo, no hay un proceso completo de contraloría por lo que, advierten, se requiere, además de la regulación, el diseño de políticas públicas.

En Estados Unidos, particularmente se han realizado esfuerzos para evaluar la efectividad de estas cámaras, como la encuesta realizada por el Center for Evidence-Based Crime Policy de la Universidad George Mason, en el que se observan efectos positivos en la relación entre policías y ciudadanos (citado en Duffy, Rahma y Timalsina, 2020).

En otras latitudes, Fernández (2019) ha estudiado el uso de las bodycam que porta la policía en España, introduciendo una importante discusión sobre la legalidad 
de estas tecnologías y, además de analizar la normativa, revisa los protocolos de actuación para garantizar un correcto trabajo de las policías. Entre las conclusiones derivadas se sostiene que el uso de las cámaras "ha quedado desfasado y rebasado por una realidad social y tecnológica en constante desarrollo" y para superar estas brechas es necesario que la policía realice propuestas de cambio legislativo para ampliar los "supuestos autorizantes" (Fernández, 2019ः 18-19).

En América Latina, Lucía Dammert y Anamaría Silva (2019) en su investigación sobre experiencias de seguridad y tecnología, refieren que el uso de cámaras corporales en Brasil y otros países han contribuido a "reducir la discrecionalidad de la policía", constituyéndose al mismo tiempo en "una alternativa para disminuir las violaciones a los derechos humanos y para aumentar la responsabilidad policial especialmente vinculado con las tareas de patrullaje y vinculación con la ciudadanía" (Dammert y Silva, 2019: 2I).

En México, Arteaga documenta la prevalencia de tecnologías de vigilancia en la función policial, e incluso destaca que en algunos casos, estas "son utilizadas por las autoridades policiales en colusión con el crimen organizado" (Arteaga, 2016: 203), y que también son monitoreadas por sus operadores a partir de prejuicios.

Asimismo, Arteaga (2018), en concordancia con los conceptos de contravigilancia planteados por Lyon (1995) y vigilancia desde abajo o sousveillance de Mann, Nolan y Wellman (2003), analiza las movilizaciones y los enfrentamientos sociales ocurridos en diciembre de 2012 durante la toma de protesta presidencial, vigilados tanto por las autoridades de los distintos órdenes de gobierno, los medios de comunicación, así como grupos activistas. En este caso, particularmente los manifestantes documentaron "abusos en el uso de la fuerza por parte de la policía, las detenciones ilegales y las acciones violentas de contención policial”. Este tipo de registros permitió documentar, como sostiene Arteaga, "el ejercicio excesivo y provocador de las fuerzas del orden" y fue un soporte para "juzgar el comportamiento público de los involucrados" (Arteaga, 2018: 65).

\section{Fuentes de información y enfoque metodológico}

Esta investigación se plantea como un ejercicio de carácter exploratorio que permita ser un punto de partida para estudios de mayor profundidad. Bajo este tenor, la estrategia metodológica utilizada es de corte cualitativo y se recurrió principalmente al análisis documental de fuentes hemerográficas y oficiales para identificar los casos 
de abuso y letalidad policial que fueron grabados por cámaras de video públicas o privadas, fijas o móviles en América Latina.

Respecto a las fuentes hemerográficas, se recurrió a los principales medios digitales de comunicación en I5 países de América Latina. Se realizaron búsquedas para identificar casos de abuso policial y ejecuciones arbitrarias captadas por cámaras de video y se sistematizó la información por país, ciudad, año de ocurrencia, autoridad involucrada, tipo de cámara, características principales de los hechos y uso social e institucional de las imágenes en video. En total se tiene registro de 92 casos que ocurrieron entre enero de 2010 y julio de 2020 en 15 países: Argentina, Bolivia, Brasil, Chile, Colombia, Costa Rica, Ecuador, El Salvador, Guatemala, Honduras, México, Nicaragua, Panamá, Paraguay y Perú.

\section{Cuadro 1.}

Casos registrados en video en América Latina documentados en esta investigación

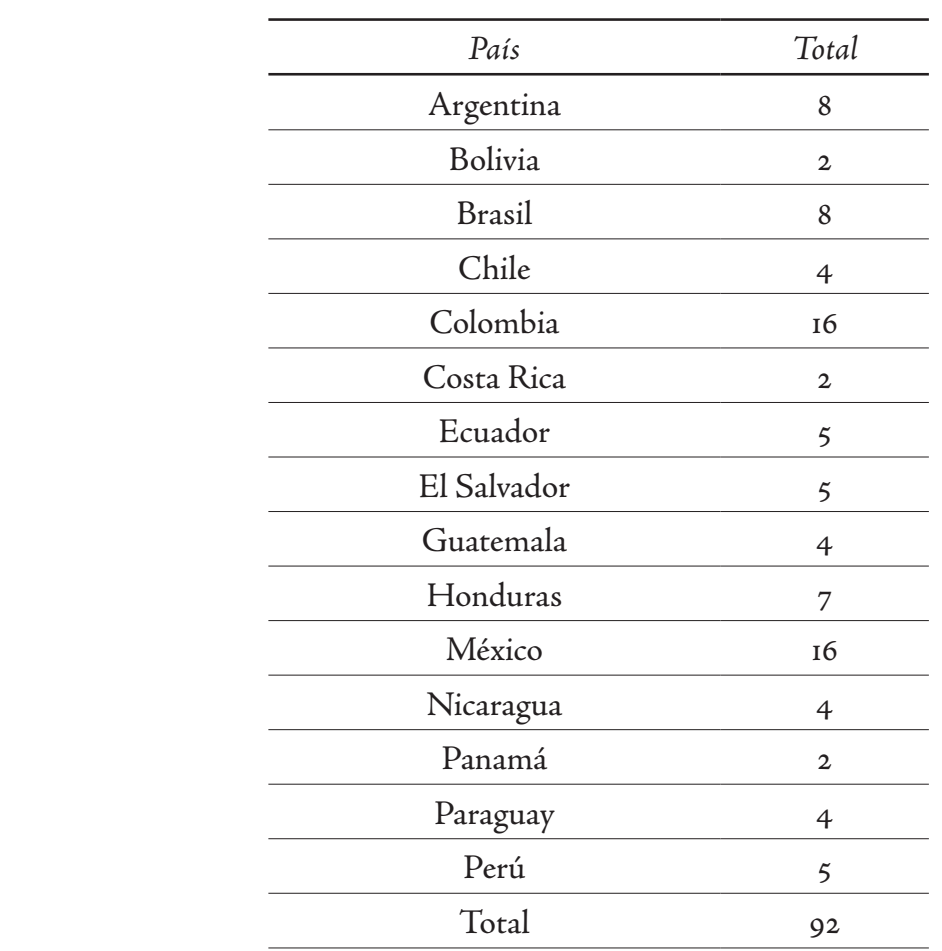

Fuente: elaboración propia. 
En relación con las fuentes oficiales se analizaron los reportes de queja y recomendaciones emitidas por OPDH en México. La base se integra por 37 casos que ocurrieron entre abril de 2006 y mayo de 2020, sistematizados por lugar de ocurrencia, fecha, año en que se emitió la recomendación, autoridad responsable, tipo de cámaras y síntesis de los hechos. Si bien este tipo de registros también existen en otros países de América Latina, los casos de México se utilizan para contrastar las narrativas de los medios de comunicación y de instituciones públicas como los OPDH.

Como punto de partida se estudiaron las frecuencias de las bases de datos con el propósito de caracterizar la problemática a partir de su análisis descriptivo. Posteriormente, para analizar las narrativas sociales e institucionales se identificaron los discursos por los distintos actores que confluyen en este fenómeno: gobierno (incluyendo a las instituciones policiales), OPDH, víctimas y medios de comunicación.

Este primer abordaje y sus hallazgos, como se precisó, son de carácter exploratorio y buscan contribuir a que esta agenda de investigación se discuta con mayor profundidad, y que posteriormente se realicen análisis más robustos que permitan analizar el quehacer policial y el uso de la fuerza en situaciones específicas.

\section{Discusión}

A pesar de la discrecionalidad con la que operan las policías en América Latina, el registro en video ha logrado documentar y evidenciar distintos casos de abuso y letalidad policial en la región. En el periodo analizado se observa una tendencia incremental en la que estas situaciones se registran por los distintos tipos de cámaras públicas y privadas, así como su difusión en los medios de comunicación y por parte de instituciones públicas que permiten visibilizar este fenómeno social.

Si bien, los casos de abuso y letalidad policial registrados en video son solo una muestra del total de los casos que realmente ocurren, aun cuando solo una parte de las grabaciones se visibilizan públicamente, estas representan evidencia suficiente para advertir acerca de la gravedad del problema y las fallas institucionales para reducir la discrecionalidad policial y las prácticas de arbitrariedad.

En la base de datos de América Latina se registraron 92 casos de abuso y letalidad policial documentados en video y difundidos públicamente por los medios de comunicación. En total se incluyen casos de is países que se enlistan en el apartado titulado: Fuentes de información y enfoque metodológico.

La mayor parte de los casos (aproximadamente 80\%) se documentaron entre enero de 2019 y julio de 2020, es decir, en los últimos años. Si bien esto podría 
deberse a la escasa disponibilidad de la información en las fuentes electrónicas y a su vez implicar un sesgo en la investigación, también es probable que represente la tendencia incremental de este fenómeno y su respectiva grabación en video y difusión en los medios de comunicación.

Brasil, Colombia, Argentina, México y Honduras son los países de los que se dispone la mayor cantidad de casos documentados. En menor proporción se presentan casos de Panamá, Bolivia y Costa Rica que en la base de datos únicamente registran dos, respectivamente.

En relación con el tipo de autoridad policial que cometió el abuso o la ejecución arbitraria se encontró que en $48.6 \%$ de los casos participó la policía nacional y en 4I.4\% la local (estatal o municipal). Es decir, se observa una mayor participación de las policías con competencia en el ámbito nacional que de las locales, aunque esta diferencia no es tan amplia.

Asimismo, se observó participación de la policía militar en casos registrados en Brasil y Honduras. En pocos de estos no es posible identificar al tipo de autoridad que comete el abuso, pero por la vestimenta, las personas que grabaron o el medio de comunicación pueden colegir que se trata de una autoridad policial.

Respecto al tipo de video que logró documentar el caso de abuso o letalidad policial se observa que $88.6 \%$ de los casos fueron grabados por cámaras privadas de teléfonos móviles, mientras que el resto fue captado por cámaras instaladas en la vía pública y por cámaras de la misma policía. Es decir, se trata de manifestaciones de sousveillance en las que se muestra la intencionalidad de exponer el abuso policial, pero también de una videovigilancia desde abajo o subvigilancia de carácter incidental que no se instala con el objetivo de vigilar a la autoridad, pero eventualmente se constituye como evidencia del comportamiento arbitrario y/o violento de la institución policial (Brucato, 2015; Newell, 2020).

Es altamente probable que un buen número de casos de abuso y letalidad policial hayan sido documentados por cámaras públicas en las ciudades, sobre todo en aquellas en que en los últimos años se ha incrementado la disponibilidad de tecnologías de videovigilancia (Arteaga, 2018; Jasso, 2020); sin embargo, como se puede ver en esta investigación, la mayor parte de los casos que se visibilizan corresponden a los registrados por cámaras privadas, es decir, por una subvigilancia incidental. 


\section{La"baja visibilidad" de la institución policial}

La marginalidad de los casos registrados en cámaras públicas y difundidos públicamente podría deberse a la discrecionalidad con la que operan las autoridades policiales. En América Latina se observa una diferencia significativa a lo planteado por Sandhu y Haggerty (2015) con respecto al estatus de la discrecionalidad policial. En este sentido, es importante precisar que, si bien el uso de cámaras ha contribuido a develar "la baja visibilidad de la policía", las tecnologías de vigilancia son un mecanismo de control y como tal están a disposición de quienes las operan y gestionan. Existe la posibilidad de que los casos de abuso policial o ejecuciones arbitrarias se omitan, oculten o eliminen, tal como se ha registrado en distintos casos en América Latina.

Sin embargo, en general no se puede obviar que los casos que se han difundido en video han generado impactos sociales al exhibir el abuso policial. Algunas videograbaciones han contribuido para exigir rendición de cuentas y control policial, e incluso se han constituido en medio de prueba para que las víctimas accedan a la justicia. Pero otros más se han quedado en el silencio, como si se tratara de abusos o "muertes que no importan" (Gayol y Kessler, 20I8). La búsqueda y sistematización realizada da cuenta de casos de abuso policial cuyas imágenes han sido invisibilizadas y de la construcción de discursos y narrativas tendientes a justificar el uso de la fuerza y a neutralizar la gravedad de los eventos.

En América Latina se registran varios casos en los que la presencia de la cámara constituye una amenaza para el quehacer policial y en los que se registró cómo las mismas autoridades, en el afán de invisibilizar el abuso policial, buscaron eliminar las cámaras.

En Brasil, donde la utilidad de las cámaras fue un tema que ganó amplia repercusión periodística poco antes de la visita del Papa, se redoblaron los controles. En ese contexto la policía mató al albañil Amarildo de Souza, un vecino de la favela Rocinha, cuyo cuerpo no fue hallado. Sin embargo, "la investigación judicial demostró que los policías de la upp de Rocinha, que están procesados y presos, desconectaron las cámaras de seguridad para ocultar el traslado del cuerpo del albañil De Souza luego de matarlo debido a las torturas a que fue sometido" (Infobae, 2013).

De forma similar ha ocurrido en México, donde los OpDH tienen registro de videos que muestran cómo la policía elimina las cámaras para deshacerse de la evidencia. En 20I7, una víctima declaró que desde el monitor de la cámara de seguridad instalada en su casa pudo observar a integrantes de la policía estatal entrando en su domicilio, pero "no se pudo obtener el video, debido a que el dispositivo fue 
dañado, posiblemente por los servidores públicos involucrados" (Recomendación $2 \mathrm{IG}, \mathrm{CNDH} 2 \mathrm{OI} 7$ 134). No obstante, cámaras privadas en domicilios vecinos lograron evidenciar los hechos.

En otro evento registrado en Monterrey en 20ro, en el que dos estudiantes "fueron abatidos a balazos frente a la puerta de su escuela"7 por elementos de la Secretaría de la Defensa Nacional (SEDENA), las videograbaciones muestran que los estudiantes "no portaba ningún arma, como los servidores públicos de la SEDENA refirieron" y además se afirma que "en el video es posible observar que también destruyeron a las $02: 06: 2$ la cámara de seguridad perimetral que se encontraba en la caseta de vigilancia" (Recomendación 45, CNDH, 2010: 24).

Además de la eliminación física de las cámaras que registran los casos de abuso y letalidad policial, existen otras formas en las que las instituciones policiales pueden omitir la evidencia. En el caso de las cámaras públicas la misma autoridad tiene el control de vigilar lo que le resulte pertinente, así como de no grabar cuando esto repercuta en su imagen pública o eliminar las imágenes que se hayan grabado (Mateescu, Rosenblat y Boyd, 2016; Duffy, Rahma y Timalsina, 2020). En síntesis, las formas de discrecionalidad son múltiples aun con la visibilidad de las imágenes que registran las cámaras.

\section{Narrativas sociales e institucionales frente a la videovigilancia}

Aun cuando los videos que se visibilizan y difunden son una muestra marginal, estos han tenido un papel central para acceder a la justicia o cuando menos reducir la discrecionalidad policial, a pesar de las resistencias institucionales que se pueden observar en las narrativas que se presentan en las siguientes páginas.

En Argentina, en 2019 se registró la ejecución de un remisero, ${ }^{8}$ quien recibió nueve balazos por agentes de la policía de la ciudad de Villa Crespo. Una cámara de seguridad captó toda la escena de lo ocurrido y "las imágenes son elocuentes, muestran a la víctima bajando de su automóvil para dirigirse a un patrullero que

7 Se trata del caso de los estudiantes Jorge Antonio Mercado Alonso y Javier Francisco Arredondo Verdugo, quienes "abandonaron la biblioteca del Instituto Tecnológico de Estudios Superiores de Monterrey (ITESM) a los 00:38 minutos del sábado 20 de marzo, y siete minutos más tarde fueron abatidos a balazos frente a la puerta de su escuela" (Carrizales y Castillo, 20Io).

8 El término remisero usado en Argentina y Uruguay refiere al conductor de transporte público. 
estaba estacionado. Cuando se acerca le disparan y luego lo rematan en el piso [... ] los primeros disparos lo tiraron al asfalto, cuando estaba agonizando intenta incorporarse y uno de los policías lo patea y le vuelve a disparar, provocándole la muerte" (La Izquierda Diario, 2019). A pesar de las contradicciones en las que cayeron los policías, las imágenes evidenciaron los hechos y se procedió penalmente contra los involucrados.

La evidencia en imagen y su difusión pública "obliga" a las autoridades a responder por los hechos, como en el caso Palmarito en Puebla, México, ${ }^{9}$ donde se publicó un comunicado de la SEDENa en el que "reiteró su disposición de colaborar en la investigación de los hechos mostrados en un video captado por cámaras de vigilancia, para verificar su autenticidad y si corresponde al lugar y fecha de los hechos en Palmarito, para que en caso de ser necesario, se deslinden las responsabilidades correspondientes" (CNN, 2017).

Pero en el otro extremo están los casos en los que aun cuando el video registre el abuso policial, la autoridad otorga la razón a la policía, e incluso concede más poder de actuación sin apego a los derechos humanos. Tal es el caso de Argentina, donde en 2018 se publicó la Resolución 956/18 que en términos coloquiales "habilita a disparar antes de preguntar" (La Izquierda Diario, 2019).

También en ese país, en 2018 se registró un "gesto histórico" (Fava, 2018) cuando Macri -entonces presidente de Argentina- recibió a Luis Chocobar, un policía que "fuera de servicio, persiguió, baleó y mató a una persona por la espalda en el marco de un violento asalto a un turista estadounidense en la ciudad de Buenos Aires". Todo esto fue registrado en video y fue ampliamente difundido; como consecuencia, el policía fue procesado por homicidio agravado y exceso en la legítima defensa. La recepción presidencial fue calificada como un respaldo del gobierno a las fuerzas policiales; se le conoció como "doctrina Chocobar" y se afirmó que "tiende a legitimar la represión ilegal" (Fava, 2018).

Como señalamos, la mayor parte de los videos de abuso y letalidad policial que se difunden fueron grabados por cámaras privadas, mayoritariamente por "vigilantes furtivos" con sus propios teléfonos móviles (Mateescu, Rosenblat y Boyd, 2016). Este

9 "El video, que se divulgó editado, muestra un vehículo que recibe algunos disparos antes de que un grupo de militares haga descender a los ocupantes del automóvil. Uno de ellos, vestido con una camisa de color oscuro, es jalado por elementos militares que lo hacen acostarse en el piso, donde permanece sometido por un tiempo mientras los soldados parecen intercambiar fuego con otras personas. Hacia el final del video se observa a varios soldados rodear al hombre y a uno de ellos apuntar su arma y disparar a quemarropa al hombre, todavía tendido boca abajo en el piso" (CNN, 2017). 
tipo de videos representan por sí mismos un importante recurso para evidenciar el abuso policial, pero los medios de comunicación juegan un papel fundamental al visibilizar masivamente los hechos y colocarlos en la agenda pública.

Como parte de nuestra investigación documentamos decenas de casos de este tipo que se difundieron en medios locales, como la ejecución extrajudicial que ocurrió en Piura, Perú, en 2015, donde el titular de prensa dice:"Ejecuciones extrajudiciales: video revela que policías mataron a delincuentes. Testigo grabó con su celular a supuestos delincuentes intervenidos ser ejecutados por policías" (América TV, 20i6). Lo relevante de este tipo de videos para Perú fue que desde el punto de vista de los medios de comunicación ofrecían "la prueba que faltaba para poder afirmar que entre los años 2012 y 2015 un grupo irregular de la Policía Nacional habría ejecutado extrajudicialmente a por lo menos 20 personas" (América TV, 2016). Es decir, permitió abrir al escrutinio público otros casos que previamente se habían registrado.

Además, los videos que captan estos casos de abuso policial potencialmente pueden convertirse en medios de prueba para que las víctimas accedan a la justicia. Pero esto no ocurre por sí solo, sino que es producto de alianzas entre la sociedad, los medios de comunicación, los OPDH y organizaciones no gubernamentales (ONG); en síntesis, de un ejercicio de sousveillance que publicita los casos y logra respuesta por parte de la sociedad y en algunos casos de las autoridades.

En suma, se observa que frente al abuso policial se desenlazan disputas asimétricas entre la sociedad y las instituciones policiales que varían de acuerdo con las particularidades de cada contexto, pero que la existencia de un video que lo visibilice llega a ser determinante para reducir la discrecionalidad de la policía.

Es preciso reconocer, sin embargo, que la numerosa existencia de videos puede llegar a ser abrumadora y a pesar de ello no ser garante del acceso a la justicia. Como en el caso Nochixtlán, ${ }^{10}$ en México, del que se tiene registro de " 873 fotografías y 318 videos del día de los hechos" (CNDH, 20I7) y después de años continúa sin resolución.

Por otra parte, se advierte que en las policías de América Latina prevalece la resistencia a visibilizar los videos públicos y solo ceden ante la petición de un tercero y bajo presión social. Entre las narrativas de la policía se argumenta la imposibilidad de grabar por tratar de repeler una agresión, se sostiene la imposibilidad de registrar

10 De acuerdo con la Comisión Nacional de Derechos Humanos (2017) "el operativo destinado a liberar vialidades estuvo indebidamente diseñado, preparado, coordinado y ejecutado, en que no se observaron plenamente los protocolos de actuación, en especial por lo que hace al uso legítimo de la fuerza y a la necesidad de priorizar el uso de mecanismos y técnicas no violentas antes de emplear la fuerza contra la población en los enfrentamientos ocurridos en Nochixtlán, Huitzo y Hacienda Blanca y Viguera". 
una intervención por fallas en el funcionamiento de los equipos, entre otras tantas posibilidades que les permitan permanecer en la opacidad.

Sin embargo, cada vez hay más formulas públicas que se orientan a acotar la discrecionalidad policial, como las acciones de complementariedad en las que oNG u OPDH acompañan a las víctimas y solicitan a las autoridades la transparencia del actuar policial, a la par que también se proveen de videos -en su mayoría privados- que les permitan ejercer presión sobre las autoridades estatales. Asimismo, ocurre que los medios de comunicación difunden un caso proporcionado por un testigo que posteriormente es retomado por los OPDH O ONG para iniciar investigaciones y determinar mediante peritajes y análisis la relevancia del material videográfico recabado.

En el caso particular de los OPDH que se analiza con mayor proximidad en el contexto mexicano, se observa que estos pugnan por fungir como reguladores para que las instituciones policiales no vulneren los derechos humanos y se apeguen a los protocolos en aras de reducir la discrecionalidad.

\section{Conclusiones}

El abuso policial es un problema público que no solo prevalece en América Latina, sino que en algunos países de la región parece agravarse. Existen tensiones entre la discrecionalidad arraigada y profundamente aceptada en las policías y el surgimiento de nuevas dinámicas de visibilidad que ofrecen los distintos tipos de tecnologías de vigilancia que cotidiana o furtivamente supervisan el quehacer policial.

La búsqueda, revisión y sistematización de los casos de abuso y letalidad policial registrados en video muestra fuertes tensiones. Por una parte, las instituciones policiales se resisten a registrar y visibilizar como un mecanismo de rendición de cuentas del quehacer policial. Por otra parte, como una forma de control social, niegan u omiten los videos captados por las cámaras públicas en los que se registran casos de abuso policial e incluso -como se documentó- llegan a destruir las cámaras que presuntamente grabaron algún hecho de abuso policial para mantenerse en la opacidad, indicativo de amplias prerrogativas para decidir sobre su propio repertorio de visibilidad.

En contraparte, la sociedad ha documentado y develado numerosos casos de abuso policial registrados en videograbaciones y en alianza con los medios de comunicación, ONG, OPDH y otros actores han sido capaces de influir para que las víctimas 
accedan a la justicia y a la reparación del daño, así como para posicionar en la agenda pública este problema que afecta a la sociedad.

No obstante la cada vez mayor visibilidad de la arbitrariedad y violencia policial, la reducción de la discrecionalidad y opacidad es un tema pendiente en las organizaciones policiales. En América Latina se identifican importantes vacíos legales que imposibilitan que los videos registrados constituyan medios de prueba. En este sentido, si bien la legislación penal reconoce estos recursos, en la práctica permanecen y prevalecen ambigüedades significativas respecto al debido proceso y los derechos fundamentales de las víctimas. También se observan numerosos casos que no logran tener el mismo eco e impacto social que los registrados en otros contextos y quedan en silencio, o cuando mucho como una nota más en la prensa.

Además, a pesar de la visibilidad que adquieren los casos, la policía tiende a negar y neutralizar el abuso policial o poner en duda la veracidad de los videos y las narrativas de las víctimas y, en los casos más extremos, se legitiman las prácticas de arbitrariedad cediendo ante la versión construida por la policía.

La agenda de investigación sobre el abuso y la letalidad policial y las tensiones entre la discrecionalidad y las tecnologías de vigilancia son amplias, sobre todo en el contexto de América Latina donde se han estudiado con menor intensidad y profundidad estas interacciones y el abuso policial es una práctica arraigada y aceptada.

Finalmente, es necesario señalar la relevancia académica y social de estudiar esta relación y sus tensiones a la luz del discurso internacional e institucional que difunde la rendición de cuentas y el control policial y que promueve, a la par, el uso de las cámaras. En América Latina hay diferencias contextuales y capacidades institucionales diferenciadas que se contraponen a la eficacia que parece mostrar el uso de tecnologías de videovigilancia sobre el actuar policial. Coincidimos con Wall y Lennermann (2014) en que estamos inmersos en un "proceso de adaptación" en el que resulta necesario enfocarse en acotar la discrecionalidad policial como una práctica que en América Latina no apunta a encontrar solución con la visibilidad que potencialmente aportan las tecnologías de vigilancia.

\section{Referencias}

Alvarado, Arturo y Carlos Silva

20II Relaciones de autoridad y abuso policial en la Ciudad de México. Revista mexicana de sociología, 73(3), pp. 445-473, Dor: http://dx.doi. org/IO.2220I/iis.01882503p.201I.3.28724. 


\section{América TV}

2016 Ejecuciones extrajudiciales: video revela que policías mataron a delincuentes. América TV, 3 de octubre de 20I6, consultado en: https://www. americatv.com.pe/noticias/actualidad/video-demostraria-que-policia-ejecuto-supuestos-delincuentes-n249295

Arteaga, Nelson

2018 Videovigilancia en México. Protesta política, conflicto y orden social, México, FLACSO, DoI: https://doi.org/IO.2307/j.ctvbiht8w

Arteaga, Nelson

2016 Regulación de la videovigilancia en México. Gestión de la ciudadanía y acceso a la ciudad. Espiral (Guadalajara), 23(66), pp. 193-238, Dor: https://doi.org/I0.32870/espiral.v23i66.530I

\section{Arteaga, Nelson}

2015 "Doing Surveillance Studies in Latin America: Insecurity context", Surveillance and Society, Canadá, I3(I), pp. 78-90, Dor: https://doi. org/10.24908/ss.vi3i1.5159.

Bittner, Egon

1970 The functions of police in modern society, EUA, National Institute of Mental Health-Center for Studies of Crime and Delincuency.

Bolaños, Omar, Silvia Benavidez y Leonardo Fabián

2017 Ejecuciones extrajudiciales en Colombia 2002-2010: Obediencia ciega en campos de batalla ficticios, Bogotá, Ediciones USTA, DOI:IO.2307/j. ctvckq9ip

Botta, Florencia

2014 "Algunos apuntes sobre la videovigilancia gubernamental en espacios públicos", Hipertextos, I (2), pp. IO4-I30, consultando enः http:/ / revistahipertextos.org/wp-content/uploads/20I4/o9/Hipertextos_no.2.104130.pdf

Brown, Gregory

2016 "The blue line on thin ice: police use of force modifications in the era of camera phones and YouTube", British Journal of Criminology, 56(2), pp. 293-312, DoI: https://doi.org/I0.IO93/bjc/azv052

Brucato, Ben

2015 "Policing Made Visible: Mobile Technologies and the Importance of Point of View", Surveillance E Society I3 (3/4), pp. 455-473, DOI: https:// doi.org/IO.24908/ss.v13i3/4.542I 
Cano, Ignacio y José Fragoso

2000 "Letalidade da acao policial no Rio de Janeiro: A actuacao da Justica Militar", Revista Brasileira de ciencias criminais, 8(30), pp. 207-233, recuperado de: https://bit.ly/3io $\mathrm{Z}_{7} \mathrm{Ob}$

Carrizales, David y Gustavo Castillo

2010 Soldados abatieron a alumnos del Tec, según fuentes castrenses, $\mathrm{La}$ Jornada, 26/03/ 2010, recuperado de: https://www.jornada.com. $\mathrm{mx} / 20 \mathrm{Io} / \mathrm{o} / 26 /$ politica/oronipol

CNN

2017 "Investigan autenticidad de video de una presunta ejecución extrajudicial en Puebla", cNN en español, Io/05/2017, consultado en: https:// cnnespanol.cnn.com/2017/05/ro/investigan-autenticidad-de-video-de-una-presunta-ejecucion-extrajudicial-en-puebla/

Comisión Nacional de Derechos Humanos

2017 Recomendación No. 2IG, CNDH: México, consultado en: https://www. cndh.org.mx/sites/default/files/documentos/2019-07/RecvG_02I.pdf

Comisión Nacional de Derechos Humanos

2017 Comunicado de Prensa DGC/342/17. 18 de octubre de 2017, CNDH, México, consultado en: https://www.cndh.org.mx/sites/all/doc/Comunicados/2017/Com_2017_342.pdf

Comisión Nacional de Derechos Humanos

2010 Recomendación No. 45, CNDH, México, consultado en: https:// www.cndh.org.mx/sites/default/files/doc/Recomendaciones/2010/ REC_2OIO_045.pdf

Dammert, Lucía y Anamaría Silva

2018 Seguridad y Tecnología en América Latina: Experiencias y Desafíos, Santiago, Universidad de Santiago de Chile.

Díaz, Leticia

2019 "Lo de Nuevo Laredo fue al estilo Tlatlaya: ejecución extrajudicial y prefabricado" (video). Proceso, 10/o9/2019, consultado en: https://www. proceso.com.mx/599243/lo-de-nuevo-laredo-fue-al-estilo-tlatlaya-ejecucion-extrajudicial-y-prefabricado-video

Duffy, Mattias, Mohamed Rahma y Prayatana Timalsina

2020 "Connection Resilient Bodycam with Built-In Non-Repudiation and Verification", EasyChair preprint no. 3230, consultado en: https://easychair.org/publications/preprint/D4NV 
Dussauge, Mauricio, Guillermo Cejudo y María del Carmen Pardo (eds.) 2018 Las burocracias a nivel de calle: una antología, CIDE, México.

Fassin, Didier

2016 Las fuerzas del orden. Una etnografía del accionar policial en las periferias urbanas, Buenos Aires, Siglo xxI Editores.

Fava, Nicolás

2018 "Discurso securitario. La doctrina Chocobar", Revista Bordes, unpaz, consultado en: https://revistabordes.unpaz.edu.ar/la-doctrina-chocobar/

Fernández, Pedro

2019 El uso policial de las bodycam y sus propuestas de mejora, España, Editorial Reus.

Foucault, Michael

2000 Vigilar y Castigar. Nacimiento de la prisión, Buenos Aires, Siglo xxI Editores.

Gayol, Sandra y Gabriel Kessler

2018 Muertes que importan. Una mirada sociobistórica de casos que marcaron la Argentina reciente, Buenos Aires, Siglo xxi Editores.

Goldstein, Joshep

1960 "Police Discretion Not to Invoke the Criminal Process: Low-Visibility Decisions in the Administration of Justice", The Yale Law Journal, 69(4), pp. 543-594, DOI:I0.2307/794445.

INFOBAE

2013 "Brasil: 700,000 cámaras vigilan Río de Janeiro camino a la Copa del Mundo", Infobae, Io/II/2013, consultado en: https://www.infobae. $\mathrm{com} / 2013 / \mathrm{II} / \mathrm{IO} / 1522715$-brasil-700000-camaras-vigilan-rio-janeirocamino-la-copa-del-mundo/

Jasso, Carmina

2020 La ciudad videovigilada. Entre la prevención del crimen y el control social, México, Instituto de Investigaciones Sociales-unAm (en dictamen).

Jobard, Fabien

20II Abusos policiales. La fuerza pública y sus usos, Buenos Aires. Prometeo. Joh, Elizabeth

2018 "Police Surveillance Machines: A Short History", Law and Political Economy (en proceso), DOI* IO.2139/ssrn.3218483 
La Izquierda Diario

2019 La Policía de la Ciudad remató al remisero en el piso [video], II/Io/20I9, consultado en: http://www.laizquierdadiario.com/Video-La-Policiade-la-Ciudad-remato-al-remisero-en-el-piso

Lyon, David

1995 El ojo electrónico. El auge de la sociedad de la vigilancia, España, Alianza Editorial.

Mann, Steve, Jason Nolan y Barry Wellman

2003 "Sousveillance: Inventing and Using Wearable Computing Devices for Data Collection in Surveillance Environments", Surveillance E Society I(3), pp. 33I-355, DoI: https://doi.org/IO.24908/ss.vii3.3344

Mateescu, Alexandra, Alex Rosenblat y Danah Boyd

2016 "Dreams of accountability, guaranteed surveillance: The promises and costs of body-worn cameras", Surveillance E Society, I4(I), pp. I22-127, DOI: 10.24908/ss.vi4iI.6282.

Mclaughlin, Eliott

2020 "Three videos piece together the final moments of George Floyd's life", cNN, OI/06/2020, recuperado de: https://edition.cnn. com/2020/o6/or/us/george-floyd-three-videos-minneapolis/index. html

Monjardet, Dominique

2010 Lo que hace la policía: Una sociología de la fuerza pública. Prometeo, Argentina.

Newell, Bryce

2020 "Introduction to dialogue section on "The state of sousveillance", Surveillance E Society, I8(2), pp. 257-26I, DoI: https://doi.org/I0.24908/ ss.vi8i2.14013.

ONU

2018 Informe de la Relatora Especial sobre las ejecuciones extrajudiciales, sumarias o arbitrarias acerca de su misión a El Salvador*

Pérez, Catalina, Carlos Silva e Ignacio Cano

2019 Monitor del uso de la fuerza letal en América Latina: Un estudio comparativo de Brasil, Colombia, El Salvador, México y Venezuela, México, CIDE/IIJ-UnAm/LAV/Fip/Open Society Fundations. 
Pita, María

2019 "Hostigamiento policial o de las formas de la violencia en barrios populares de la Ciudad de Buenos Aires. Relato de una investigación”, Desacatos, 60, mayo-agosto, pp. 78-93, DoI: https://doi.org/IO.29340/60.209I. Sandhu, Ajay y Kevin Haggerty

2015 "High-Visibility Policing: Policing on Camera and the Crisis of Police Legitimacy", Oxford Handbooks online, DoI: I0.1093/ oxfordhb/9780199935383.013.80.

Smith, Michael, Robert Kaminski, Jeffrey Rojek, Geoffrey Alpert y Jason Mathis 2007 "The impact of conducted energy devices and other types of force and resistance on officer and suspect injuries", Policing: An International Journal of Police Strategies and Management, 30(3), Dor: I0.1108/13639510710778822.

Sozzo, Máximo

2017 La Inflación Punitiva. Un análisis comparativo de las mutaciones del derecho penal en América Latina (1990-2015), México, FLACSO.

Stinson, Phillipe

2020 Criminology Explains Police Violence, Oakland, CA, University of California Press, DOI* I0.2307/j.ctvxihtxx.

UNODC

2019 Global Study on homicide. Homicide: extent, patterns, trends and criminal justice response, Viena, United Nations Office on Drugs and Crime.

Wall, Tyler y Travis Linnemann

2014 "Staring Down the State: Police Power, Visual Economies, and the 'War on Cameras"', Crime, Media, Culture, Io(2), pp. I33-I49, Dor: https:// doi.org/IO.II77/I741659014531424.

Westley, William

I953 "Violence and the Police", American Journal of Sociology, 59, pp. 34-4I.

Carmina Jasso

Doctora en Políticas Públicas por el Centro de Investigación y Docencia Económicas A. C. (CIDE). Investigadora de tiempo completo del Instituto de Investigaciones Sociales de la unam (irsunam) y profesora de la Facultad de Ciencias Políticas y Sociales de la UNAM (FCPys UNAM). Sus principales líneas de investigación son la seguridad y las políticas públicas para la reducción y prevención de la criminalidad. 
Carolina Jasso

Politóloga por la Facultad de Ciencias Políticas y Sociales de la Universidad Nacional Autónoma de México, egresada de la Especialidad en Seguridad Pública del pueCPYS-UNAM y maestranda en Ciencia Social con especialidad en sociología por El Colegio de México. Sus intereses y líneas de investigación son seguridad, violencia y derechos humanos.

Citar como: Lucía Carmina Jasso López y Carolina Jasso González (202I), "Abuso policial, discrecionalidad y tecnologías de vigilancia en América Latina", Iztapalapa. Revista de Ciencias Sociales y Humanidades, núm. 90, año 42, enero-junio de 202I, ISSN: 2007-9176; pp. II9-I44. Disponible en $<$ http://revistaiztapalapa.izt.uam.mx/index.php/izt/issue/archive $>$. 